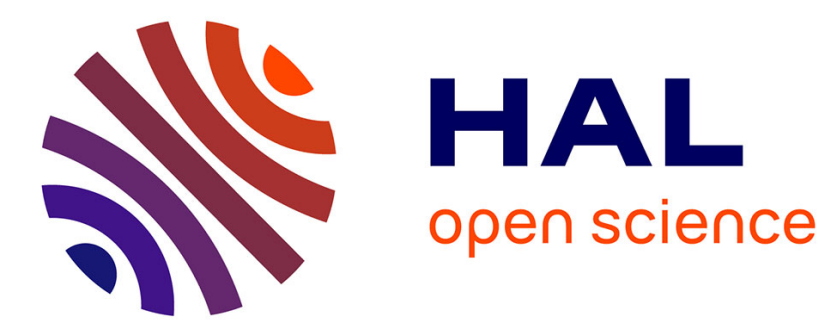

\title{
Sol-gel synthesis and crystallization kinetics of dysprosium-titanate Dy2Ti2O7 for photonic applications
} Jan Mrázek, Michel Potel, Jiří Buršík, Aleš Mráček, Anna Kallistová, Šárka Jonášová, Jan Boháček, Ivan Kašík

\section{- To cite this version:}

Jan Mrázek, Michel Potel, Jiř́ Buršík, Aleš Mráček, Anna Kallistová, et al.. Sol-gel synthesis and crystallization kinetics of dysprosium-titanate Dy2Ti2O7 for photonic applications. Materials Chemistry and Physics, 2015, 168, pp.159-167. 10.1016/j.matchemphys.2015.11.015 . hal-01231146

HAL Id: hal-01231146

https://hal-univ-rennes1.archives-ouvertes.fr/hal-01231146

Submitted on 3 Dec 2015

HAL is a multi-disciplinary open access archive for the deposit and dissemination of scientific research documents, whether they are published or not. The documents may come from teaching and research institutions in France or abroad, or from public or private research centers.
L'archive ouverte pluridisciplinaire HAL, est destinée au dépôt et à la diffusion de documents scientifiques de niveau recherche, publiés ou non, émanant des établissements d'enseignement et de recherche français ou étrangers, des laboratoires publics ou privés. 


\title{
Sol-gel synthesis and crystallization kinetics of dysprosium-titanate $\mathrm{Dy}_{2} \mathrm{Ti}_{2} \mathrm{O}_{7}$ for photonic applications
}

Jan Mrázek ${ }^{1}$, Michel Potel ${ }^{2}$, Jiř́ Buršík ${ }^{3}$, Aleš Mráček ${ }^{4,5}$, Anna Kallistová ${ }^{6,7}$, Šárka Jonášová ${ }^{6}$ Jan Boháček ${ }^{1}$, Ivan Kašík ${ }^{1}$

${ }^{1}$ Institute of Photonics and Electronics AS CR, v.v.i., Chaberská 57, 18251 Prague 8, Czech Republic

2 Université de Rennes 1, Sciences Chimiques de Rennes, UMR-CNRS 6226, Campus de Beaulieu, CS74205, F-35042 Rennes Cedex, France

3 Institute of Physics of Materials AS CR, v.v.i., Žižkova 22, 61662 Brno, Czech Republic

4 Centre of Polymer Systems, University Institute, Tomas Bata University in Zlín, T. Bati 5678, 760

01 Zlin, Czech Republic.

5 Department of Physics and Material Engineering, Faculty of Technology, Tomas Bata University in Zlín, nám. Vavreckova 275, 76001 Zlín, Czech Republic

6 Institute of Geology AS CR, v. v. i., Rozvojová 269, 16500 Prague 6, Czech Republic

7 Institute of Geochemistry, Mineralogy and Mineral Resources, Faculty of Science, Charles

University, Albertov 2, Prague 2, 128 43, Czech Republic

Corresponding author:

Jan Mrázek

Institute of Photonics and Electronics AS CR, v.v.i

Chaberská 57

18251 Prague 8

Czech Republic

Tel: +420266773558

Fax: +420284680222

E-mail:mrazek@ufe.cz

\begin{abstract}
We present a generic sol-gel approach for the preparation of nanocrystalline $\mathrm{Dy}_{2} \mathrm{Ti}_{2} \mathrm{O}_{7}$. This approach allows the preparation of powders and highly transparent thin films having nanocrystals of a tailored size. The thermal evolution of these nanocrystals was followed by conventional structural methods and furthermore, we determine both the kinetic parameters of the nanocrystal nucleation process from amorphous xerogel as well as the crystallization mechanism. The crystallization temperature was $798 \pm 2{ }^{\circ} \mathrm{C}$. The nanocrystal growth started by homogeneous nucleation with a constant nucleation rate followed by three dimensional growth. The activation energy of the crystallization was $780 \mathrm{~kJ} \cdot \mathrm{mol}^{-1}$, and the energy of nanocrystal growth was 24.4 $\mathrm{kJ} \cdot \mathrm{mol}^{-1}$. We demonstrate the existence of pure pyrochlore structure of $\mathrm{Dy}_{2} \mathrm{Ti}_{2} \mathrm{O}_{7}$ with the lattice parameter $\underline{a}$ equal to $10.2 \AA$. The structural evolution of nanocrystalline thin films was identical to that of the evolution of xerogels. A thin film of thickness $342 \mathrm{~nm}$ exhibited an optical transmission of $93.39 \%$ with a refractive index of 2.138 at $935 \mathrm{~nm}$. These results provide fundamental information about the crystallization behavior of $\mathrm{Dy}_{2} \mathrm{Ti}_{2} \mathrm{O}_{7}$ : they can be used to prepare pure nanocrystalline xerogels and highly transparent thin films with tailored structural properties which are suitable for photonic applications.
\end{abstract}

\section{Research highlights}

Sol-gel route to nanocrystalline xerogels and thin films of $\mathrm{Dy}_{2} \mathrm{Ti}_{2} \mathrm{O}_{7}$ was presented.

Fundamental information about the nucleation process and crystal growth was evaluated. 
Thermal and structural evolution of powders was compared with thin films.

Basic structural and optical properties of prepared films were evaluated.

\section{Keywords}

A1. Nucleation

A2. Sol-gel

B1. Nanomaterials

B1. Rare earth compounds

\section{Introduction}

Lanthanide titanium oxides, which crystallize in the face-centered cubic (FCC) pyrochlore structure with the general formula $\mathrm{A}_{2} \mathrm{~B}_{2} \mathrm{O}_{7}[1]$, have attracted close attention of recent material research. The reason lies in the extraordinary physical properties of the pyrochlore structure. In the pyrochlore structure, the sites of A-cations are occupied by ions of rare-earth elements (RE), the sites of B-cations are occupied by titanic ions [2]. The spins of atoms at A and B sites are arranged on the vertices of corner sharing tetrahedrons. These tetrahedrons are linked together into an infinite three-dimensional network allowing intensive spin interactions within the crystal lattice. Such an arrangement brings variety of magnetic properties that depend on the RE incorporated within the pyrochlore crystal lattice [3]. Dysprosium titanate $\mathrm{Dy}_{2} \mathrm{Ti}_{2} \mathrm{O}_{7}$ has been particularly studied for its spin-ice behavior [4] and recently it has attracted attention as a novel photo-catalyzer [5]. Such potential applications place high demands on the quality of prepared materials.

Beside various solid-state and mechano-chemical synthesis [6-8], which are limited by high processing temperatures above $1100^{\circ} \mathrm{C}$, a number of soft-chemical approaches to nanocrystalline $\mathrm{Dy}_{2} \mathrm{Ti}_{2} \mathrm{O}_{7}$ were proposed. Combination of the sol-gel approach with the organic ligands, i.e. citric acid [5] or stearic acid [9] allowed to prepare highly uniform nanocrystalline $\mathrm{Dy}_{2} \mathrm{Ti}_{2} \mathrm{O}_{7}$ at calcination temperatures lower than $800{ }^{\circ} \mathrm{C}$. Despite the fact that the lowered calcination temperature is a great technological advantage, none of introduced soft-chemical approaches has been successfully used to prepare transparent thin films of $\mathrm{Dy}_{2} \mathrm{Ti}_{2} \mathrm{O}_{7}$. To the best of our knowledge pure $\mathrm{Dy}_{2} \mathrm{Ti}_{2} \mathrm{O}_{7}$ films were prepared only by epitaxial growth assisted by pulse laser deposition [10]. Sol-gel approach was applied to prepare other pyrochlore thin films, such a $\mathrm{Nd}_{2} \mathrm{Ti}_{2} \mathrm{O}_{7}$ [11]. However, the surface variation of prepared films was on the level of several hundred of nanometers.

In this contribution we present generic sol-gel approach to nanocrystalline $\mathrm{Dy}_{2} \mathrm{Ti}_{2} \mathrm{O}_{7}$ powders and highly transparent thin films. Kinetic parameters of the nucleation process and the crystallization mechanism of the formation of nanocrystalline $\mathrm{Dy}_{2} \mathrm{Ti}_{2} \mathrm{O}_{7}$ from amorphous xerogels are studied. Thermal and structural evolution of formed nanocrystalline powders is compared with the evolution of nanocrystalline thin films. Optical properties of prepared films were evaluated. Presented results provide fundamental information about the crystallization behavior of nanocrystalline $\mathrm{Dy}_{2} \mathrm{Ti}_{2} \mathrm{O}_{7}$ and they can be used for preparation of pure nanocrystalline xerogels and highly transparent thin films with tailored structural properties which are suitable for photonic applications.

\section{Experimental}

\subsection{Materials and sample preparation}

Samples were prepared by the sol-gel method followed by the thermal treatment of 
formed gel. Typically, a total of $6 \mathrm{~g}$ titanium(IV)butoxide (Fluka, Purum) was dissolved in $250 \mathrm{ml}$ of absolute ethanol (Sigma-Aldrich, Spectranal grade). Then a total of $7.74 \mathrm{~g}$ of dysprosium(III) nitrate pentahydrate (Alfa Aesar, 99.9\%) was dispersed in the solution. All precursors were used as purchased without further purification. The mixture was stirred under ambient temperature to form transparent solution. Formed solution was refluxed at $86^{\circ} \mathrm{C}$ for $24 \mathrm{~h}$ and then allowed to cool. The solution was purified by a filtration through a $0,4 \mu \mathrm{m}$ PTFE membrane and concentrated on a rotary evaporator. Prepared sol was divided into two parts.

The first part of sol was used to prepare thin films. The sol was deposed by a spincoating method on a silica substrates (Technical glass products, USA). Typically, $150 \mu$ of sol was dropped on the substrate and rotated at 1500 RPM for $60 \mathrm{~s}$. The layer was densified in a rapid thermal annealing furnace (RTA) AccuThermo AW410 (Allwin21 corporation) at $550^{\circ} \mathrm{C}$ for $60 \mathrm{~s}$ under an oxygen flow $51 \cdot \mathrm{min}^{-1}$. The heating rate was $5{ }^{\circ} \mathrm{C} \cdot \mathrm{s}^{-1}$. Three layers were subsequently deposed in this way. Finally, prepared multilayer films were thermally treated with a heating rate of $20{ }^{\circ} \mathrm{C} \cdot \mathrm{s}^{-1}$ to the temperatures ranging from $800^{\circ} \mathrm{C}$ to $1200^{\circ}$ for $60 \mathrm{~s}$ under an oxygen flow of 10 $1 \cdot \mathrm{min}^{-1}$.

Remaining part of the sol was dried up on a rotary evaporator. The resulting gel was pulverized and calcined to temperatures between $800^{\circ} \mathrm{C}$ and $1200^{\circ} \mathrm{C}$ for 30 minutes forming xerogels. The calcinations were carried out under a $101 \cdot \mathrm{min}^{-1}$ flow of oxygen.

\subsection{Characterization methods}

Differential thermal analyses (DTA) and thermal gravimetry (TG) measurements were performed on a DTG $60 \mathrm{H}$ (Shimadzu) multifunctional apparatus. The samples were analyzed at different heating rates from 5 to $40^{\circ} \mathrm{C} \cdot \mathrm{min}^{-1}$ under an oxygen flow $50 \mathrm{ml} \cdot \mathrm{min}^{-1}$.

The FT-IR spectra of the xerogels were recorded with a Vector 22 (Bruker) single channel spectrometer. Approximately $4 \mathrm{mg}$ of the analyzed xerogel was mixed with $200 \mathrm{mg}$ of $\mathrm{KBr}$ (Sigma-Aldrich, 98\% FT-IR grade) finely pulverized in a mortar and pressed into a pellet. A pellet made of pure $\mathrm{KBr}$ was used as a reference sample.

The X-ray diffraction analyses (XRD) were realized on a Bruker D8 Discover diffractometer with the Bragg-Brentano geometry operating with the $\mathrm{Cu}-\mathrm{K} \alpha$ radiation $(\lambda=1.54056$ $\AA$, operating voltage $40 \mathrm{kV}$, current $40 \mathrm{~mA}$, integration time $200 \mathrm{~ms}$ ). The size of the formed nanocrystals, D, was calculated using Scherrer's equation -Eq. (1) [12]:

$$
D=\frac{k \cdot \lambda}{\beta \cdot \cos \theta}
$$

where $\mathrm{k}$ is a structural factor equal to $0.89, \lambda$ is the $\mathrm{X}$-ray wavelength, here $0.154056 \mathrm{~nm}$, is the correlated FWHM value corresponding to the (222)-plane peak of $\mathrm{Dy}_{2} \mathrm{Ti}_{2} \mathrm{O}_{7}$ at the diffraction angle 2 equal to 30.697 degrees. The crystallized phase was compared to JCPDS data file number 170453 of $\mathrm{Dy}_{2} \mathrm{Ti}_{2} \mathrm{O}_{7}$.

Transmission electron microscope (TEM) analyses of the xerogels were carried out on a Philips CM12 STEM electron microscope. A copper grid coated with a porous carbon support film was used as a sample holder. The analyzed xerogel was dispersed in ethanol, and the resulting suspension was treated in an ultrasonic bath for 10 minutes and then applied to the grid. Scanning electron microscope (SEM) images were taken with a TESCAN Lyra 3 XMU FEG/SEM device. The composition of individual grains and the overall composition of the xerogels heat-treated at $1200{ }^{\circ} \mathrm{C}$ were measured on a Cameca SX 100 electron microprobe. The samples were excited by the X-ray radiation beam of the energy equal to $15 \mathrm{keV}$. Beam current was $60 \mathrm{~mA}$. A thin carbon layer was sputtered on the samples prior to analysis to prevent charging.

Raman spectra were recorded on a Renishaw Invia apparatus. The in-build green laser emitting at $633 \mathrm{~nm}$ with the output power of $50 \mathrm{~mW}$ was employed as the excitation source. The ultra steep long-pass edge filter allowed collecting the Raman signal with the Raman shift higher 
than $150 \mathrm{~cm}^{-1}$.

UV-VIS transmission spectra were recorded on a Lambda EZ 210; PerkinElmer; spectrometer.

The surface morphology of thin films was analyzed by an atomic force microscopy (AFM); Digital Instruments/Veeco, Woodbury, NY; in the contact mode using a Dimension 3100 AFM operated in air. Commercial $\mathrm{Si}_{3} \mathrm{~N}_{4}$ cantilevers (DI) with an elastic modulus of $0.56 \mathrm{~N} \cdot \mathrm{m}^{-1}$ were used.

\section{Results and discussion}

\subsection{Thermal behavior of xerogels}

\subsubsection{Thermal analysis of xerogels}

Calcination of xerogels is a complex process consisting of several steps. It usually involves evaporation of volatile substances, burning of organic compounds, decomposition of inorganic ligands, and the crystallization process. The results of thermal analyses are depicted in Fig. 1a. The DTA curves showed multiple endothermic peaks below $300{ }^{\circ} \mathrm{C}$, a dominant exothermic peak at around $380^{\circ} \mathrm{C}$ and an exothermic peak at $841^{\circ} \mathrm{C}$. The multiple endothermic peaks below $380^{\circ} \mathrm{C}$ were accompanied by a regular weight loss. Two smaller weight losses were related to exothermic peaks at around $380^{\circ} \mathrm{C}$ and at $841^{\circ} \mathrm{C}$.

FT-IR spectra of calcined xerogels were recorded to clarify the origin of DTA peaks. The results are depicted in Fig. 2. Thermally unprocessed xerogel exhibited several absorption bands in FT-IR spectrum. A dominant absorption band, located from 2800 to $3600 \mathrm{~cm}^{-1}$, corresponded to the vibrational bands of $-\mathrm{OH}$ groups of ethanol and alkoxy groups. Multiple absorption bands located from 1300 to $1650 \mathrm{~cm}^{-1}$ corresponded to the vibrational spectra of nitrates presented in xerogel [13]. These intensive bands overlapped the absorption band of unreacted -OH groups located at around $1638 \mathrm{~cm}^{-1}$ [14]. Since the broad peak ranging from 2800 to $3600 \mathrm{~cm}^{-1}$ had not been observed in the xerogel calcined at $300{ }^{\circ} \mathrm{C}$ it should be concluded that the endothermic peak located on DTA curve below $300^{\circ} \mathrm{C}$ is related to the evaporation and oxidation of remaining ethanol and butanol which had been released during the hydrolysis of titanium(IV)butoxide. The intensity of the absorption bands of nitrates was strongly decreased in the sample calcined above $300{ }^{\circ} \mathrm{C}$. Thus the first exothermic peak located at $380^{\circ} \mathrm{C}$ should be related to the burn-out of nitrates. However, a part of nitrates remained in the xerogel up to $840{ }^{\circ} \mathrm{C}$. These nitrates act as ligands stabilizing the dysprosium ions inside amorphous matrix as in the case of crystallization of $\mathrm{Eu}_{2} \mathrm{Ti}_{2} \mathrm{O}_{7}$ from amorphous xerogel [15]. Once the remaining nitrates had been burn-out the crystallization of the $\mathrm{Dy}_{2} \mathrm{Ti}_{2} \mathrm{O}_{7}$ occurred and the crystallization peak appeared on DTA curve at 844 ${ }^{\circ} \mathrm{C}$.

The DTA analysis is a dynamic process. The position of the crystallization peak $T_{p}$ on the thermal curve depends on the heating rate $\alpha$. The shift of the crystallization peak is widely used to calculate many thermodynamic parameters. The crystallization temperature can be calculated from the Lasocka equation -Eq. (2) that can be expressed in the following form [16]:

where $T_{c}$ is the crystallization peak position for the heating rate of $1 \mathrm{~K} \cdot \mathrm{min}^{-1}, A_{c}$ is an experimental constant. The parameters are accessible via the linear fit of the dependence of the position of the crystallization peak $T_{p}$ on the heating rate $\alpha$. Experimental data including the linear fit are depicted in Fig. 3. Calculated value of the crystallization temperature was equal to $798 \pm 2{ }^{\circ} \mathrm{C}$. This value is fully comparable with the crystallization temperatures of other RE pyrochlores prepared by the solgel method, e.g. $790{ }^{\circ} \mathrm{C}$ for $\mathrm{Nd}_{2} \mathrm{Ti}_{2} \mathrm{O}_{7}$ [11], and significantly lower than the temperatures that are necessary to the formation of RE pyrochlores by common solid state reactions, e.g. $1100{ }^{\circ} \mathrm{C}$ for $\mathrm{Er}_{2} \mathrm{Ti}_{2} \mathrm{O}_{7}, \mathrm{Nd}_{2} \mathrm{Ti}_{2} \mathrm{O}_{7}[17]$. 


\subsubsection{Nucleation process and crystal growth}

The crystallization mechanism is a key factor which affects the structural properties of formed nanocrystals. The type of the nucleation affects the homogeneity of the structure, the shape and the size distribution of formed nanocrystals. From the viewpoint of the crystallization kinetics two types of nucleation mechanism can be distinguished; site-saturated nucleation and nucleation with constant rate of nucleation. Site-saturated nucleation is characterized by the formation of the crystallization nuclei at the same time in the whole volume of the amorphous material. The growth of formed nuclei into larger nanocrystals occurs after the nucleation. Site-saturated nucleation leads to the materials with highly uniform shape and narrow size distribution of formed nanocrystals. Nucleation with constant rate of nucleation is characterized by continuous formation of nucleus simultaneously with the growth of formed nanocrystals. Formed materials exhibit lower uniformity and large size distribution of formed nanocrystals comparing with the site-saturated nucleation [18].

The type of the nucleation mechanism can be evaluated from the shape of the crystallization peak. The theoretical basis for the description of nucleation-growth processes under non-isothermal conditions have been formulated by Johnson, Mehl and Avrami. The proposed models have been summarized by Christian [18]. The type of the nucleation mechanism is determined by the value of the Avrami parameter $n$, which can be calculated from a Johnson-MehlAvrami equation -Eq. (3) expressed in the Ozawa modification for linear heating rates [19]:

$$
-n=\left.\frac{d\{\log [-\ln (1-\psi)]\}}{d \log \alpha}\right|_{T},
$$

where Avrami parameter $\mathrm{n}$ is determined from the slope of the plot $\log [-\ln (1-)]$ vs. $\log \alpha$. is the volume fraction of a crystallized material, and $\alpha$ is the heating rate. The value of is calculated as the ratio of the partial integration area of the crystallization peak at temperature $T$ over the total area of the crystallization peak. The Avrami parameter $\mathrm{n}$ can be assigned to the characteristic values which correspond to the type of nucleation and growth mechanisms. These values, together with corresponding nucleation and growth processes, are summarized in Table 1. Each grade of the Avrami parameter represent one dimension of crystal growth or a formation of nuclei. Therefore the values of the Avrami parameter for nucleation with constant rate of nucleation are higher than the values for the site-saturated nucleation. In spite of proposed theoretical model the real crystallization usually combines several processes, so the Avrami's parameter varies between predicted values.

Calculated Avrami parameters are depicted in Fig. 4. Despite relatively large error the high value of the Avrami parameter close to 4 indicates that the crystallization started by the homogeneous nucleation with constant nucleation rate. The nucleation was accompanied by threedimensional growth of nanocrystals. The transport of the matter to the formed nanocrystals was limited by the mass transport through the phase-boundary between the amorphous and crystallized part of the xerogel. Once the formed nanocrystals had made the network inside the amorphous xerogel, the mass transfer has been limited, and thus diffusion controlled mass transfer has become the main transfer mechanism. The change of the reaction mechanism reduced the values of the Avrami parameter below 2.5. Finally, once all the amorphous part of the xerogel was fully crystallized, the formation of further nuclei was terminated, cellular recrystallization occurred, and further growth of nanocrystals has been controlled by the diffusion of matter. Consequently the values of the Avrami parameter decreased below 1.

The proposed nucleation mechanism was validated by the SEM analyses of prepared xerogels. Selected results are depicted in Fig. 5. The xerogel calcined at $1200^{\circ} \mathrm{C}$ was fully crystalline and completely filled by formed nanocrystals. However, the uniformity and size distribution of the nanocrystals were highly variable. The size of formed nanocrystals ranged between 40 and $200 \mathrm{~nm}$. The xerogel was composed by large nanocrystals together with smaller 
one. Such a structural properties are typical for nanocrystalline xerogels whose crystallization mechanism proceeds in the manner of homogeneous nucleation with constant rate of nucleation. Similar structural properties has been already demonstrated on zinc titanates [20].

To evaluate the activation energy of crystallization processes, three approximations represented by Ozawa equation -Eq. (4) [21], Kissinger [22] equation -Eq. (5), and Augis-Bennett equation -Eq. (6) [23], respectively, were considered:

$$
\begin{aligned}
\ln (\alpha)= & -\frac{E_{A}}{R \cdot T_{P}}+c \\
\ln \left(\frac{\alpha}{T_{P}^{2}}\right)= & -\frac{E_{A}}{R \cdot T_{P}}+\ln \left(\frac{A \cdot R}{E_{A}}\right) \\
& \ln \left(\frac{\alpha}{T_{P}-T_{0}}\right)=-\frac{E_{A}}{R \cdot T_{P}}+\ln K_{0}
\end{aligned}
$$

The symbol means the heating rate, $\mathrm{T}_{\mathrm{p}}$ is the position of the crystallization peak, $\mathrm{T}_{0}$ is equal to $273.15 \mathrm{~K}$ and represents the conversion to Celsius scale, $\mathrm{E}_{\mathrm{A}}$ is the activation energy of the crystallization, $\mathrm{A}$ is the pre-exponential factor, $\mathrm{K}_{0}$ is the frequency factor, $\mathrm{R}$ is the ideal gas constant and $\mathrm{c}$ is the additive constant. Calculated values of the terms on the left side of the equations plotted against the reciprocal absolute temperature for selected approximations and their corresponding linear fits are depicted in Fig. 6. The calculated values of the $E_{a}$ are summarized in Table 2. All three approximations provided similar values of the activation energy close to $780 \mathrm{~kJ} \cdot \mathrm{mol}^{-1}$. This value is comparable with the values determined for other titanates prepared by sol-gel or hydrothermal methods. For example, the published value for europium titanate is $707 \mathrm{~kJ} \cdot \mathrm{mol}^{-1}[15]$, and values for barium strontium titanates range from 400 to $430 \mathrm{~kJ} \cdot \mathrm{mol}^{-1}$ [24]. The differences between these previously measure values and the values shown in Fig. 6a and Fig. $6 \mathrm{~b}$ can be attributed to the different structural and chemical composition of each material.

\subsection{Structural properties of nanocrystals}

\subsubsection{Thermal evolution of nanocrystals}

XRD patterns of calcined samples are depicted in Fig. 7. In agreement with the calculated crystallization temperature the first diffraction pattern was observed in the xerogel calcined at $800{ }^{\circ} \mathrm{C}$. The diffraction patterns corresponded to dysprosium titanate $\mathrm{Dy}_{2} \mathrm{Ti}_{2} \mathrm{O}_{7}$ pyrochlore structure. The samples were formed by pure nanocrystals without any traces of sideformed oxides. The electron microprobe analysis confirmed the chemical composition of formed nanocrystals corresponding to the formula $\mathrm{Dy}_{1.97} \mathrm{Ti}_{2.03} \mathrm{O}_{7.00}$. The deviation from the theoretical composition was within the instrumental error of the measurement. Comparing with the xerogels, the thin films diffraction patterns exhibited a lower signal-to-noise ratio. Such an observation is natural due to the limited thickness of the analyzed films thus the lower intensity of the recorded signal. The mean sizes of formed nanocrystals calculated from the Scherrer's equation are depicted in Fig. 8. The calculated mean size of formed nanocrystals regularly grew up with increasing calcination temperature from $35 \mathrm{~nm}$ up to $120 \mathrm{~nm}$. The nanocrystals constituting the xerogels were slightly bigger than the nanocrystals constituting the films. The variation in sizes between the xerogels and the films should be attributed to the different heating mechanisms which were used for sample processing. The difference is obvious for temperatures above $1000{ }^{\circ} \mathrm{C}$. The activation energy of nanocrystal growth was calculated from following equation -Eq. (7) [24]: 


$$
\log (D)=\frac{-E_{A-G}}{2.303 \cdot R} \cdot \frac{1}{T}+A
$$

where $\mathrm{D}$ mean the average nanocrystal size, $\mathrm{E}_{\mathrm{A}-\mathrm{G}}$ is the activation energy of the nanocrystal growth, $\mathrm{R}$ is the ideal gas constant, $\mathrm{A}$ is the constant. The values of the term $-\mathrm{E}_{\mathrm{A}-\mathrm{G}} /(2.303 \cdot \mathrm{R})$ are accessible by fitting the plot of $\log (\mathrm{D})$ versus the reciprocal absolute temperature $(1 / \mathrm{T})$ as can be seen in Fig. 9. In spite of the different size of nanocrystals constituting the xerogels and the films, the trends of both fits were very similar. So the calculated values of the activation energy of nanocrystal growth were equal to $24.4 \pm 1.4 \mathrm{~kJ} \cdot \mathrm{mol}^{-1}$ and $23.5 \pm 2.4 \mathrm{~kJ} \cdot \mathrm{mol}^{-1}$ for xerogels and thin films, respectively. These values well matched the values $12.3 \mathrm{~kJ} \cdot \mathrm{mol}^{-1}$ and $26.5 \mathrm{~kJ} \cdot \mathrm{mol}^{-1}$ calculated for nanocrystalline $\mathrm{Nd}_{2} \mathrm{Ti}_{2} \mathrm{O}_{7}$ [11] and $\mathrm{Eu}_{2} \mathrm{Ti}_{2} \mathrm{O}_{7}$ [15], respectively, which were prepared by the sol-gel method.

The XRD analyses of xerogels were supported by the TEM observations which are depicted in Fig. 10. The xerogel calcined at $800^{\circ} \mathrm{C}$ was composed of fine nanocrystals with the size ranging from $10 \mathrm{~nm}$ up to $40 \mathrm{~nm}$ around the mean size calculated from the Scherrer s equation. The nanoparticles grew up with increasing calcination temperature and their size was increased. Relatively wide range of observed nanocrystal sizes around the calculated nanocrystal sizes supports the proposed nucleation mechanism. The corresponding ring diffraction patterns proved that the nanocrystals were randomly oriented in the xerogel. The diffraction patterns measured on particular nanocrystals confirmed that the nanocrystals crystallized in the FCC lattice with the lattice parameter a equal to $10.2 \AA$. Such a value is in good accordance with the value a equal to $10.106 \AA$ specified in the JCPDS data file.

\subsubsection{Raman analyses of nanocrystals}

Structural data obtained from XRD analysis were supported by the Raman spectroscopy to exclude the presence of partially crystallized side-formed phases. The structure of cubic pyrochlore can be expressed by a general formula $\mathrm{A}_{2} \mathrm{~B}_{2} \mathrm{O}(1)_{6} \mathrm{O}(2)$ with two distinct oxygen sublattices [1]. This structure belongs to the space group $F d 3 m$ (n227) with $Z=8$. The site symmetry is $D_{3 d}$ for REE and $\mathrm{Ti}^{4+}$ ions, $\mathrm{C}_{2 v}$ for $\mathrm{O}(1)$ ions and $\mathrm{T}_{\mathrm{d}}$ for $\mathrm{O}(2)$ ions. According to the group theory, the pyrochlore structure displays six Raman-active modes distributed among three irreducible representations -Eq. (8) [1]:

Recorded Raman spectra are depicted in Fig. 11. The general shape of recorded spectra and the peak positions corresponded to the Raman spectra recorded on polycrystalline $\mathrm{Dy}_{2} \mathrm{Ti}_{2} \mathrm{O}_{7}$ that was prepared by solid-state reaction [25]. The most intensive peak located around $308 \mathrm{~cm}^{-1}$ was assigned to the $\mathrm{F}_{2 \mathrm{~g}}$ bending modes, the peak located around $518 \mathrm{~cm}^{-1}$ was assigned to the $\mathrm{Ag}_{\mathrm{g}}$ stretching mode and the weakest peak around $699 \mathrm{~cm}^{-1}$ corresponded to $2^{\text {nd }}$ order scattering effects. $E_{\mathrm{g}}$ mode was not observed. The Raman spectrum of the thin film was modulated by a sinusoid which had an origin in interferences of the excitation laser beam on the sample. The absence of the peaks corresponding to side-formed $\mathrm{TiO}_{2}$ or $\mathrm{Dy}_{2} \mathrm{O}_{3}$ fully proved the high purity of prepared $\mathrm{Dy}_{2} \mathrm{Ti}_{2} \mathrm{O}_{7}$.

\subsection{Properties of thin films}

The key advantage of the sol-gel method lies in its flexibility that allows to prepare both powders and thin films. Proposed approach provided crack-free, homogenous, transparent thin films as was demonstrated on films calcined at $1200^{\circ} \mathrm{C}$. The AFM surface profile of the film is depicted in Fig. 12. The film surface was composed of regularly distributed nanocrystals. Lateral dimensions of the nanocrystals ranged between 40 and $200 \mathrm{~nm}$ in accordance withe the SEM measurements depicted in Fig. 5. Maximal height difference of the surface was $16.7 \mathrm{~nm}$ and the standard roughness deviation (RMS) was $2.57 \mathrm{~nm}$. The total film thickness, determined from SEM measurements, was $342 \mathrm{~nm}$. Achieved values demonstrated superior quality of prepared films over 
the films of $\mathrm{Nd}_{2} \mathrm{Ti}_{2} \mathrm{O}_{7}$ which displayed height difference on the level of several hundred of nanometers [11].

High transparency and uniformity of prepared film were reflected in corresponding UVVIS absorption spectrum which is depicted in Fig. 13. Transmission curve displayed interference pattern reaching the value of transmission maxima of the interference fringes $\mathrm{T}_{\mathrm{o} \text {-max }}$ equal to 93.39 $\%$ at $719 \mathrm{~nm}$ and the value of adjacent transmission minima $\mathrm{T}_{\mathrm{o}-\min }$ equal to $71.44 \%$ at $935 \mathrm{~nm}$. The transmission was decreased toward shorter wavelengths due to the absorption and scattering phenomena on nanocrystals. The gap located at $330 \mathrm{~nm}$ should be attributed to the absorption edge of the silica substrate. Although the value of $\mathrm{T}_{\mathrm{o}-\max }$ could give an impression that the film showed poor optical quality it had the origin in the reflection and interference phenomena on prepared film. The optical transmission $T_{o}$ of a thin film on a substrate of an infinite thickness is a complex function -Eq.(9) [26]:

where $\lambda, n_{\text {film }}, n_{\text {sub }}, \alpha_{\text {film }}, d$ mean the wavelength, the refractive index of the film, the refractive index of the substrate, the absorption coefficient of the film, and the thickness of the film, respectively. For highly transparent thin films with $\alpha=0$ following equations for $\mathrm{T}_{\mathrm{o} \text {-max }}-$ Eq. $(10)$, and for $\mathrm{n}_{\text {film }}$ -Eq (11), can be expressed as [26]:

It should be noted that for proposed assumptions the value $T_{\text {o-max }}$ is independent on the properties of analyzed film thus $\mathrm{T}_{\mathrm{o}-\max }$ depends only on the refractive index of the substrate. For the value $\mathrm{n}_{\text {sub }}$ of the silica glass at $719 \mathrm{~nm}$ equal to 1.454 [27] Eq. 10 provided the value $\mathrm{T}_{\mathrm{o} \text {-max }}$ equal to $93.39 \%$. Calculated value was completely identical to the measured value $T_{0 \text {-max }}$ proving that relatively low transmission of prepared film was not caused by the film quality but by the fundamental optical principles. Eq. 11 provided the value $\mathrm{n}_{\text {film }}$ at $935 \mathrm{~nm}$ equal to 2.138 . This value is slightly smaller than a value of the refractive index of pure titanium dioxide which is equal to 2.4944 [27]. The assumption $\alpha=0$ was not satisfied for shorter wavelengths and the values $T_{\text {o-max }}$ were slightly decreasing due to the absorption and scattering phenomena. Correct interpretation and theoretical calculation of the transmission in this spectral region require more advanced model and exceed the scope of this paper. Feasibility of demonstrated approach together with high refractive index and unique magnetic properties of $\mathrm{Dy}_{2} \mathrm{Ti}_{2} \mathrm{O}_{7}$ open up possibilities for photonic applications. Beside the introduced potential applications $[4,5]$ the challenging combination of magnetic properties with optical one can be used for the construction of integrated optical systems [28], preparation of optical coatings [29], construction of Bragg mirrors and resonators [30] etc.

\section{Conclusions}

A generic sol-gel approach to nanocrystalline $\mathrm{Dy}_{2} \mathrm{Ti}_{2} \mathrm{O}_{7}$ was presented. Presented approach allowed to prepare powders and highly transparent thin films with tailored size of formed nanocrystals. Kinetic parameters of the nucleation process of nanocrystals from the amorphous xerogel and the crystallization mechanism were determined. The nanocrystal growth started by homogeneous nucleation with constant nucleation rate followed by three dimensional growth. The structural evolution of nanocrystalline thin films was identical to the evolution of the xerogels. Optical properties of prepared thin films were evaluated. Presented results provided fundamental information about the crystallization behavior of $\mathrm{Dy}_{2} \mathrm{Ti}_{2} \mathrm{O}_{7}$ and they could be used for preparation of pure nanocrystalline xerogels and highly transparent thin films with tailored structural properties. 


\section{Acknowledgements}

The authors acknowledge the financial support from the Czech Science Foundation under contract $\mathrm{N}^{\mathrm{o}} 102 / 13 / 37368 \mathrm{P}$.

\section{References}

[1] M. Glerup, O.F. Nielsen, F.W. Poulsen, J. Solid State Chem., 160 (2001) 25-32.

[2] S.T. Bramwell, M.J.P. Gingras, Science, 294 (2001) 1495-1501.

[3] A. Nag, P. Dasgupta, Y.M. Jana, D. Ghosh, J. Alloys Compd., 384 (2004) 6-11.

[4] R. Siddharthan, B.S. Shastry, A.P. Ramirez, A. Hayashi, R.J. Cava, S. Rosenkranz, Phys. Rev. Lett., 83 (1999) 1854-1857.

[5] L. Zhang, H. Zhong, W. Zhang, L. Lu, X. Yang, X. Wang, J. Alloys Compd., 463 (2008) 466470.

[6] A.V. Shlyakhtina, D.A. Belov, S.Y. Steafanovich, E.A. Nesterova, O.K. Karyagina, L.G. Shcherbakova, Solid State Ionics, 230 (2013) 52-58.

[7] A.F. Fuentes, K. Boulallya, M. Maczka, J. Hanuza, U. Amador, Solid State Sciences, 7 (2005) 343-353.

[8] S. Hayun, T.B. Tran, J. Lian, A.F. Fuentes, A. Navrotsky, Acta Mater., 60 (2012) 4303-4310.

[9] W. Zhang, L. Zhang, H. Zhong, L. Lu, X. Yang, X. Wang, Mater. Charact., 61 (2010) 154-158.

[10] L. Bovo, X. Moya, D. Prabhakaran, Y.-A. Soh, A.T. Boothroyd, N.D. Mathur, G. Aeppli, S.T. Bramwell, Nature Communications, 5 (2014).

[11] M.R. Mohammadi, D.J. Fray, Mater. Chem. Phys., 122 (2010) 512-523.

[12] J.I. Langford, A.J.C. Wilson, J. Appl. Crystallogr., 11 (1978) 102-113.

[13] J. Baltrusaitis, J. Schuttlefield, J.H. Jensen, V.H. Grassian, PCCP, 9 (2007) 4970-4980.

[14] D. Boyer, G. Bertrand-Chadeyron, R. Mahiou, Opt. Mater., 26 (2004) 101-105.

[15] J. Mrazek, M. Surynek, S. Bakardjieva, J. Bursik, I. Kasik, J. Cryst. Growth, 391 (2014) 25-32.

[16] M. Lasocka, Materials Science and Engineering, 23 (1976) 173-177.

[17] M. Uno, A. Kosuga, M. Okui, K. Horisaka, S. Yamanaka, J. Alloys Compd., 400 (2005) 270275.

[18] J.W. Christian, The Theory of Transformations in Metals and Alloys (Part I + II), 1st Ed. ed., Hardbound, 2002.

[19] J. Malek, T. Mitsuhashi, J. Am. Ceram. Soc., 83 (2000) 2103-2105.

[20] J. Mrazek, L. Spanhel, M. Surynek, M. Potel, V. Matejec, J. Alloys Compd., 509 (2011) 40184024.

[21] T. Ozawa, Bull. Chem. Soc. Jpn., 38 (1965) 1881-1886.

[22] J. Llopiz, M.M. Romero, A. Jerez, Y. Laureiro, Thermochim. Acta, 256 (1995) 205-211.

[23] J.A. Augis, J.E. Bennett, J. Therm. Anal., 13 (1978) 283-292.

[24] Y.S. Chang, Y.H. Chang, I.G. Chen, G.J. Chen, Y.L. Chai, J. Cryst. Growth, 243 (2002) 319326.

[25] M. Maczka, J. Hanuza, K. Hermanowicz, A.F. Fuentes, K. Matsuhira, Z. Hiroi, J. Raman Spectrosc., 39 (2008) 537-544.

[26] R. Swanepoel, Journal of Physics E-Scientific Instruments, 16 (1983) 1214-1222.

[27] E.D. Palik, Handbook of optical constants of solids, Academic Press, Orlando, 1985.

[28] F. Wang, Z.V. Vardeny, J. Mater. Chem., 19 (2009) 1685-1690.

[29] L.M. Fortes, M.C. Goncalves, R.M. Almeida, Y. Castro, A. Duran, J. Non-Cryst. Solids, 377 (2013) 250-253.

[30] R.M. Almeida, A.C. Marques, A. Chiasera, A. Chiappini, M. Ferrari, J. Non-Cryst. Solids, 353 (2007) 490-493. 
Table 1. Values of the exponent $\mathrm{n}$ for Johnson-Mehl-Avrami equation for different kinds of reaction mechanisms (adapted from [18])

\begin{tabular}{|c|c|c|c|}
\hline Type of nucleation & $\begin{array}{c}\text { Mechanisms of } \\
\text { nucleation } \\
\text { and the subsequent } \\
\text { growth }\end{array}$ & $\begin{array}{l}\text { Phase-boundary } \\
\text { controlled growth }\end{array}$ & $\begin{array}{l}\text { Diffusion controlled } \\
\text { growth }\end{array}$ \\
\hline Site-saturated & Bulk mechanism & & \\
\hline $\begin{array}{l}\text {-saturation of } \\
\text { nucleation }\end{array}$ & $\begin{array}{l}\text { One-dimensional } \\
\text { growth }\end{array}$ & 1 & 0.5 \\
\hline \multirow[t]{4}{*}{ sites prior to growth } & $\begin{array}{c}\text { Two-dimensional } \\
\text { growth }\end{array}$ & 2 & 1 \\
\hline & $\begin{array}{c}\text { Three-dimensional } \\
\text { growth }\end{array}$ & 3 & 1.5 \\
\hline & Surface mechanism & & \\
\hline & $\begin{array}{c}\text { Two-dimensional } \\
\text { growth }\end{array}$ & $\sim 2$ & 1 \\
\hline \multirow{6}{*}{$\begin{array}{c}\text { Constant rate of } \\
\text { homogenous } \\
\text { nucleation during the } \\
\text { process }\end{array}$} & Bulk mechanism & & \\
\hline & $\begin{array}{c}\text { One-dimensional } \\
\text { growth }\end{array}$ & 2 & 1.5 \\
\hline & $\begin{array}{c}\text { Two-dimensional } \\
\text { growth }\end{array}$ & 3 & 2 \\
\hline & $\begin{array}{c}\text { Three-dimensional } \\
\text { growth }\end{array}$ & 4 & 2.5 \\
\hline & Surface mechanism & & \\
\hline & $\begin{array}{l}\text { Two-dimensional } \\
\text { growth }\end{array}$ & $\sim 3$ & $\sim 2$ \\
\hline
\end{tabular}

Table 2. Activation energy of crystallization calculated using different approximations

\begin{tabular}{ccc}
\hline $\begin{array}{c}\text { Ozawa's } \\
\text { approximation } \\
\left(\mathrm{kJ} \cdot \mathrm{mol}^{-1}\right)\end{array}$ & $\begin{array}{c}\text { Kissinger's approximation } \\
\left(\mathrm{kJ} \cdot \mathrm{mol}^{-1}\right)\end{array}$ & $\begin{array}{c}\text { Augis-Bennett's } \\
\text { approximation } \\
\left(\mathrm{kJ} \cdot \mathrm{mol}^{-1}\right)\end{array}$ \\
\hline $766 \pm 44$ & $778 \pm 44$ & $793 \pm 44$ \\
\hline
\end{tabular}



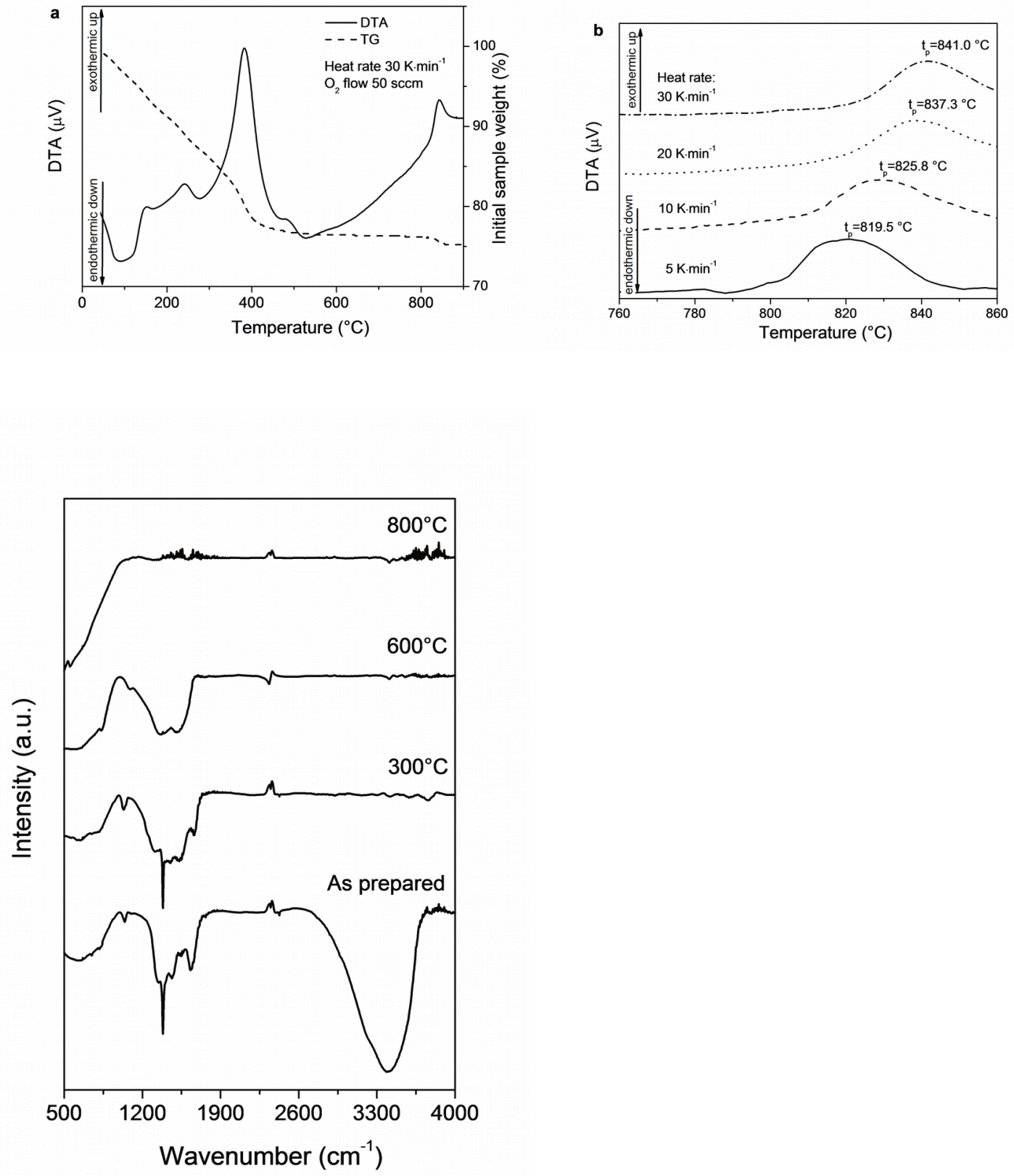

Fig. 1. Thermal analyses of xerogels. (a) DTA and TG records for heat rate $30 \mathrm{~K} \cdot \mathrm{min}^{-1}$ and (b) zoom on the crystallization peaks for particular heat rates.

Fig. 2. Thermal dependence of FT-IR spectra.

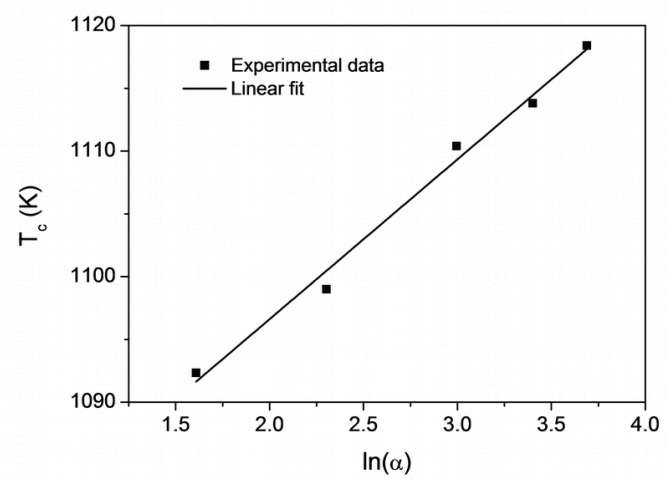


Fig. 3. Thermal shift of the crystallization peaks and the corresponding fit.

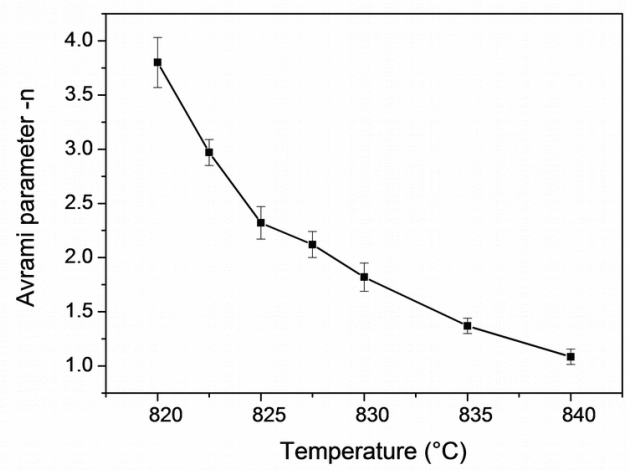

Fig. 4. Calculated values of Avrami's parameter.

Fig. 5. SEM images of xerogels calcined at $1200 \mathrm{C}$.

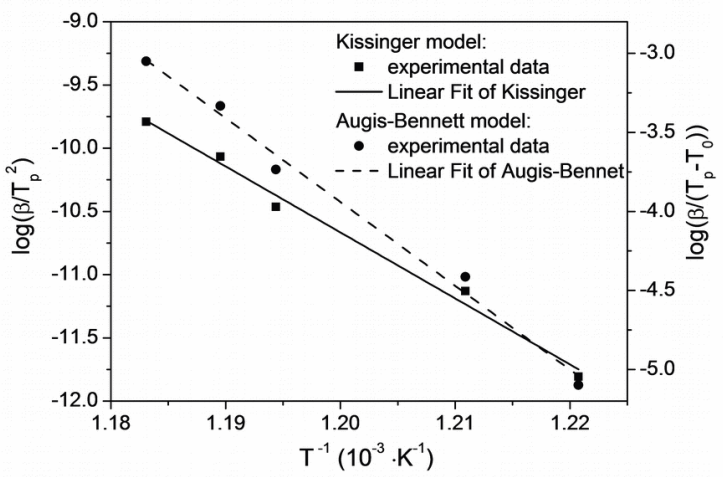


Fig. 6. Plots of the Kissinger (left scale) and Augis-Bennett (right scale) equations.

Fig. 7. XRD patterns of calcined samples with denoted (hkl) indices. (a) Xerogels and (b) thin films.

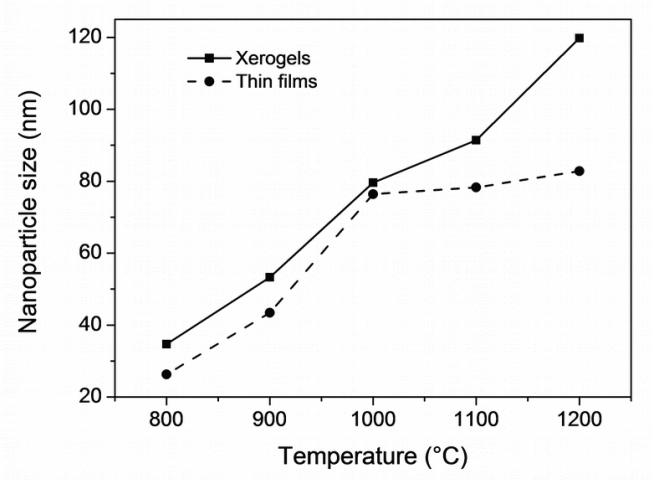

Fig. 8. Nanoparticle sizes calculated from the Scherrer's equation.

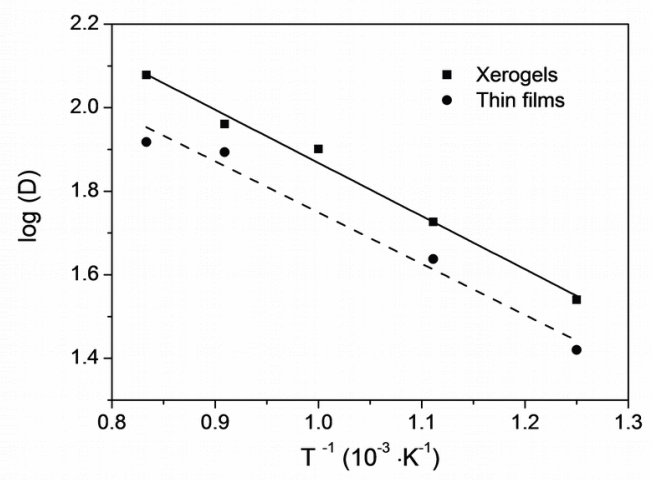

Fig. 9. Calculation of the activation energy of the nanocrystal growth 

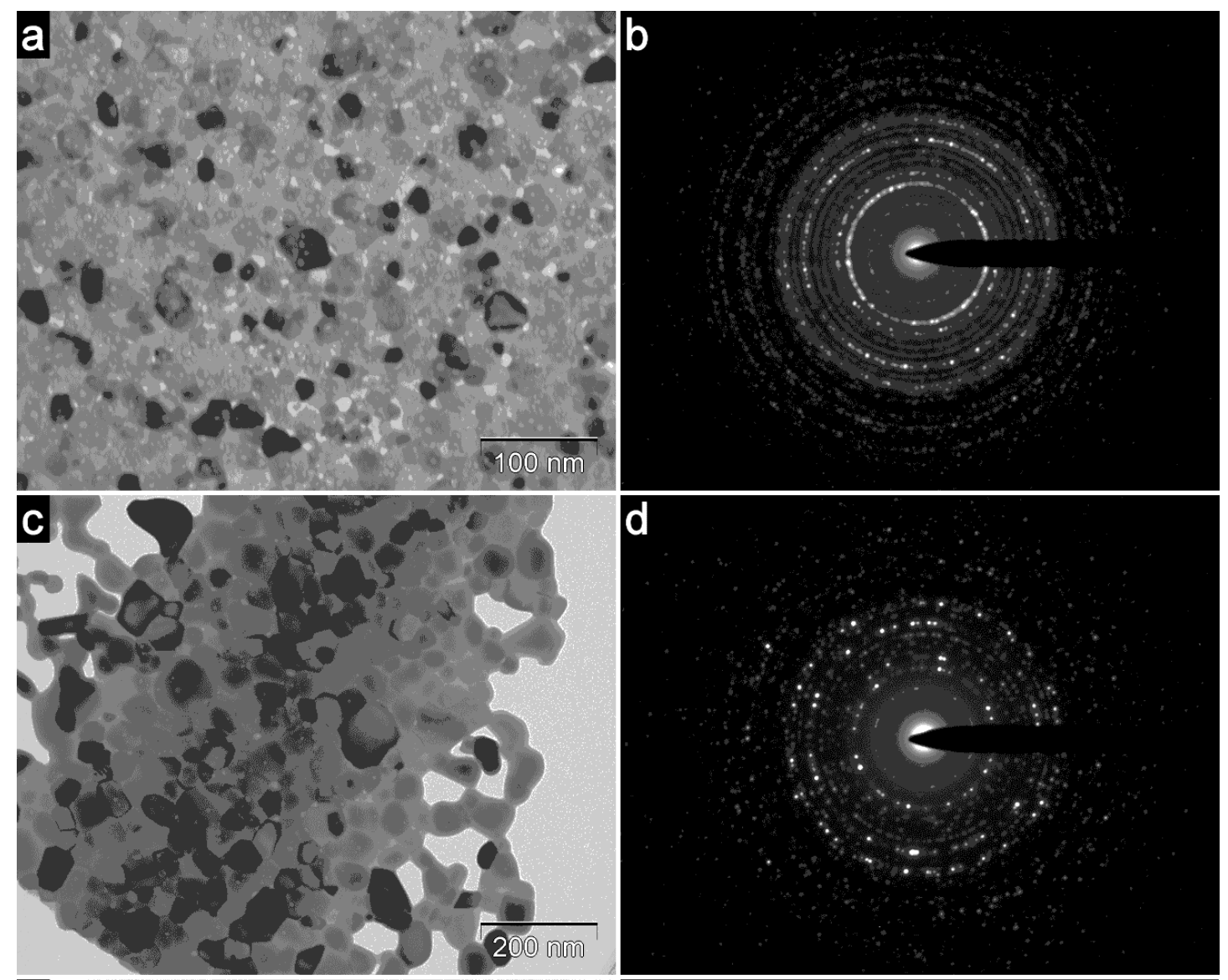

e
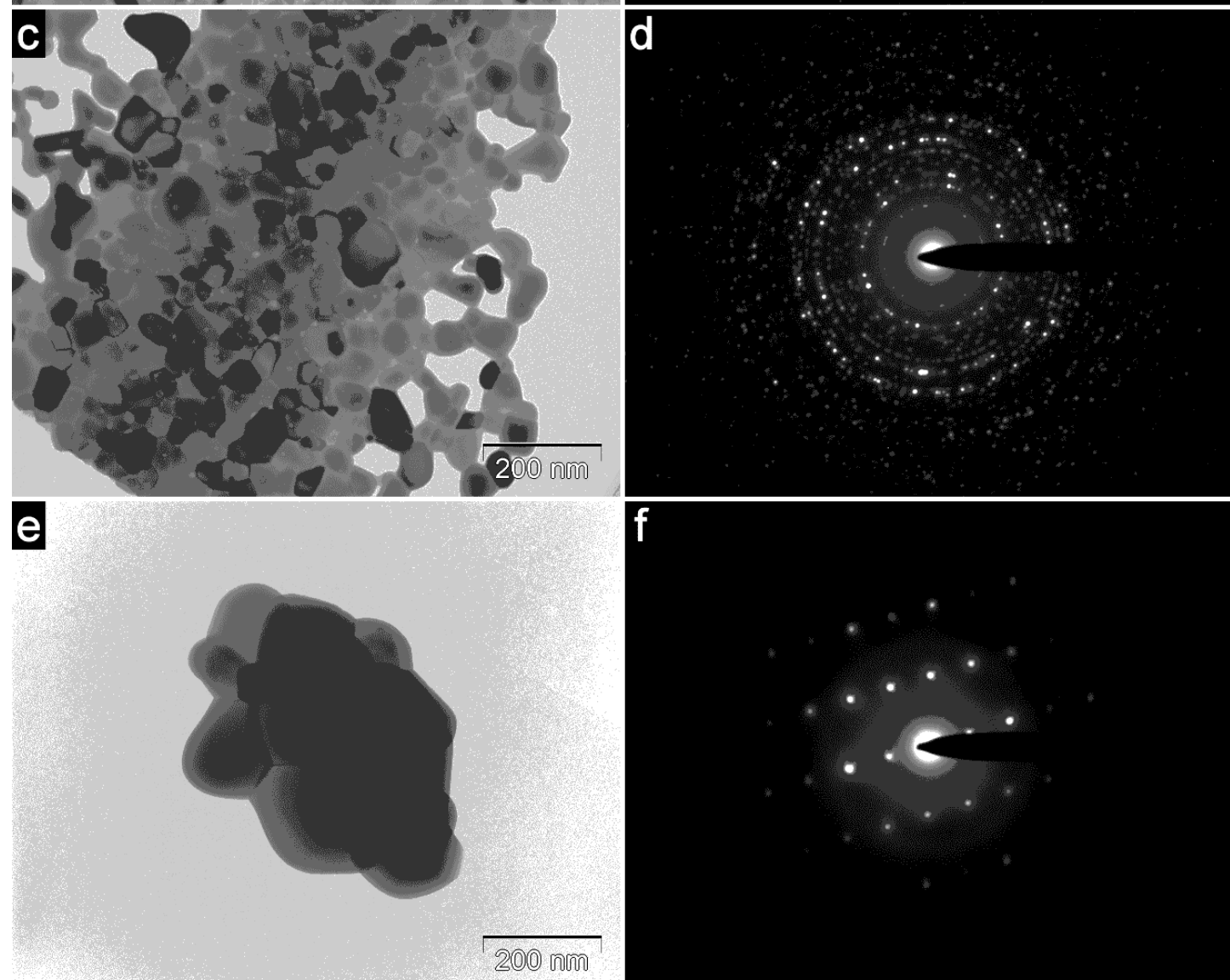

f

Fig. 10. TEM

images of the xerogels: (a) overall view on xerogel calcined at $800{ }^{\circ} \mathrm{C}$ and (b) corresponding diffraction pattern. (c) Overall view on xerogel calcined at $1200{ }^{\circ} \mathrm{C}$ and (d) corresponding diffraction pattern. (e) Zoom on selected grain and (f) the diffraction pattern corresponding to the zone axis [310]. 


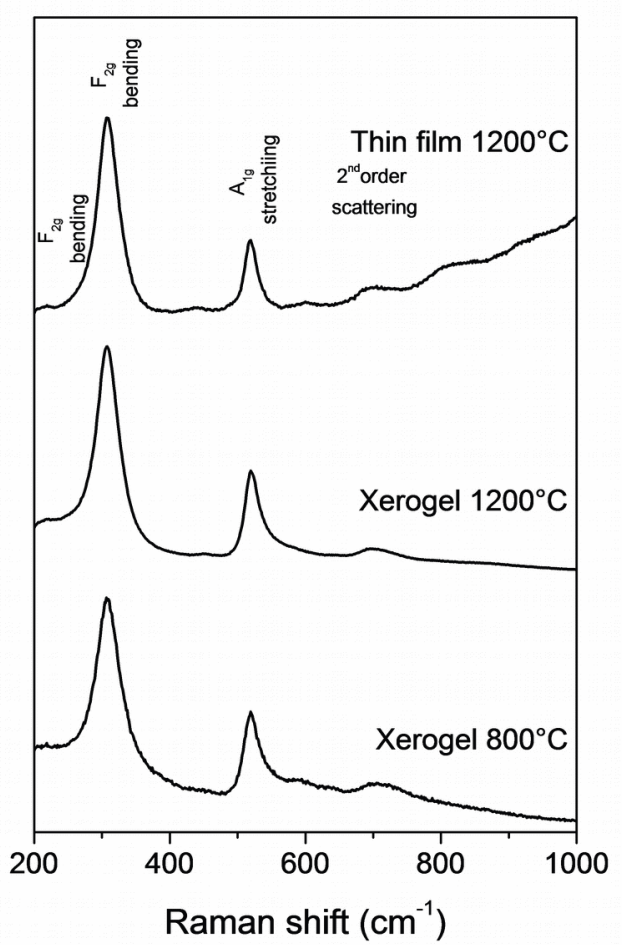

Fig. 11. Raman spectra of xerogels and thin film.

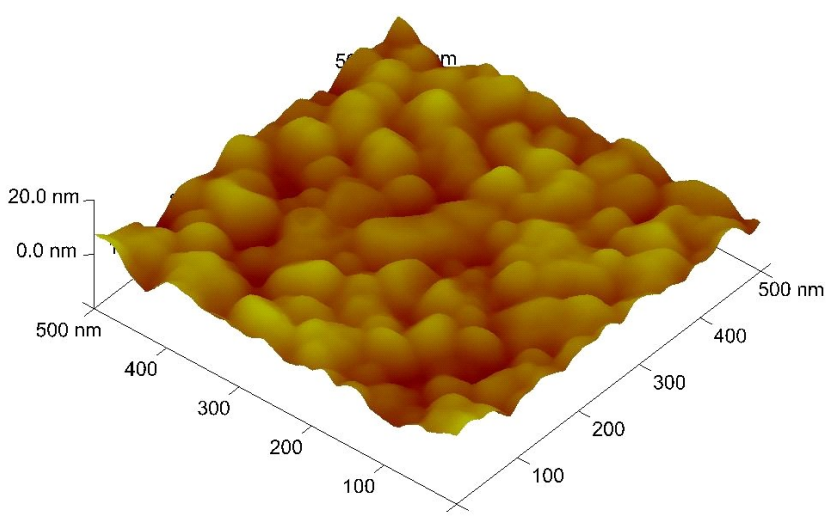


Fig. 12 AFM surface profile of thin film calcined at $1200{ }^{\circ} \mathrm{C}$

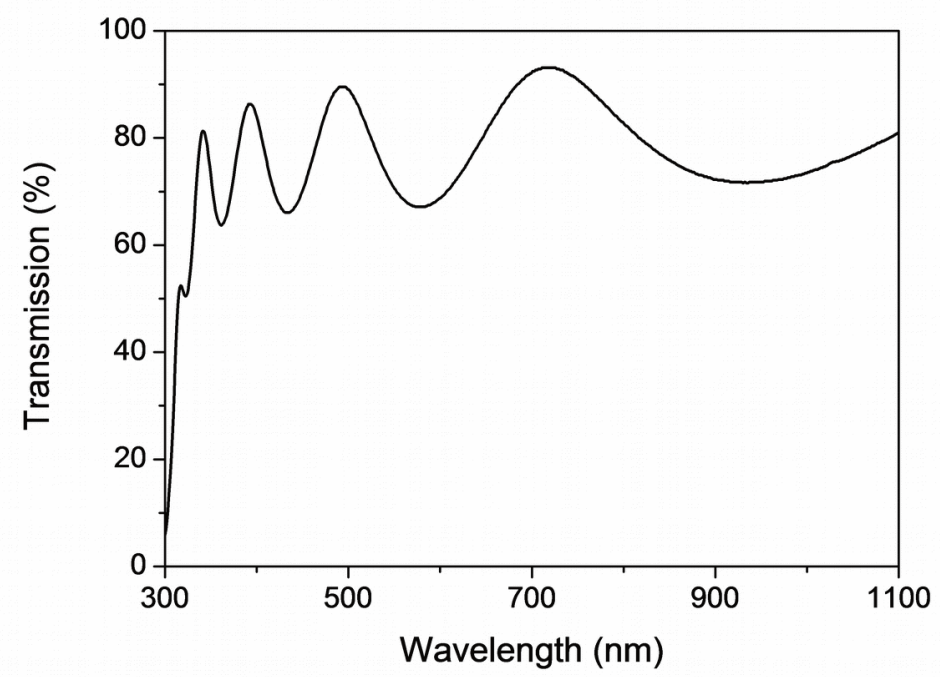

Fig. 13 UV-VIS absorption spectra of prepared film calcined at $1200{ }^{\circ} \mathrm{C}$ 